\title{
A relação entre o preço pago pelo consumidor de carne bovina em Santa Maria e o recebido pelo produtor de gado de corte no Rio Grande do Sul, Brasil
}

\author{
Relationship between price paid by consumers in Santa Maria and prices paid to beef cattle farmers \\ in Rio Grande do Sul, Brazil
}

João Garibaldi Almeida Viana ${ }^{\mathrm{I}}$ Vicente Celestino Pires Silveira ${ }^{\mathrm{II}}$

\section{RESUMO}

Este estudo analisa em que medida os preços pagos pelos consumidores de carne bovina - ponto final da cadeia - são repassados ao produtor. Os preços dos diferentes cortes de carne foram coletados através de pesquisa mensal de preços, em quatro supermercados de Santa Maria, RS, Brasil. Depois de obtidos os valores percentuais dos diferentes cortes na composição da carcaça, estes valores foram multiplicados pelo preço pago pelo consumidor, obtendo-se assim os preços e as proporções dos cortes referentes ao valor ajustado de um quilo de carcaça pago pelo consumidor. Para a obtenção do preço médio do $\mathrm{kg}$ do boi vivo recebido pelos produtores, foram considerados os preços coletados pela EMATER-RS. Verificou-se uma baixa variação ao longo do ano das partes componentes da carcaça, na contribuição do preço total. $\mathrm{Na}$ média, o dianteiro contribui com 26,10\%, o costilhar com $13,40 \%$ e o traseiro com $60,50 \%$ do preço total da carcaça. O setor a jusante na cadeia bovina tem função reguladora do preço final ao consumidor, com uma margem de operação de 7,61 pontos ao longo do ano. Nos três quadrimestres ao longo do ano, a associação entre o preço recebido pelo produtor (PRP) e o pago pelo consumidor (PPC) teve um comportamento diferenciado. As associações verificadas foram fraca, negativamente forte e positivamente muito forte para o primeiro, segundo e terceiro quadrimestres, respectivamente.

Palavras-chave: bovinocultura de corte, carne bovina, cadeia de carne bovina.

\section{ABSTRACT}

This study analyses how much of prices paid by the consumers of beef meat are passed on to the farmer. The prices of different types of beef cuts were collected monthly in four supermarkets in Santa Maria-RS, Brazil. The percentage values of different cuts were obtained and multiplied by the price paid by consumers. Thus, it was calculated the adjusted price of kilogram of carcass commercialized at supermarket. The average price per kilogram of live steers received by the farmer was collected by EMATER-RS. There was a low price variation throughout the year of carcass cuts, when referring to the price of the whole carcass. In average, the Forequarter represented $26.10 \%$, the Sidecut $13.40 \%$ and the Sawcut $60.50 \%$ of the total price. The roll of the post farm production sectors in maintaining a low consumer price variation with a reduced margin variation of 7.6 points during the year was made evident. The relation between the prices received by farmer and the prices paid by consumers for each four-month period of the year present different results: weakness, strength negative and strength positive associations in the first, second and third periods, respectively.

Key words: beef cattle, beef, beef chain.

\section{INTRODUÇÃO}

Os produtores de bovino de corte observaram, nos últimos anos, que o preço do quilograma do boi vivo se manteve relativamente constante, porém os preços dos insumos apresentaram elevação. Essa situação trouxe um panorama de queda na renda dos pecuaristas, levando muitos produtores a vender parte de suas terras ou a deixar o ramo pecuário.

O agronegócio é visto como a cadeia produtiva que envolve desde a fabricação de insumos, passando pela produção nos estabelecimentos agropecuários e pela transformação do produto até o consumo (GASQUES et al., 2004). No caso da bovinocultura de corte, existem basicamente quatro

${ }^{\text {I} C u r s o ~ d e ~ P o ́ s-g r a d u a c ̧ a ̃ o ~ e m ~ E x t e n s a ̃ o ~ R u r a l, ~ U n i v e r s i d a d e ~ F e d e r a l ~ d e ~ S a n t a ~ M a r i a ~(U F S M), ~ S a n t a ~ M a r i a, ~ R S, ~ B r a s i l . ~}$

"Departamento de Educação Agrícola e Extensão Rural, UFSM, Prédio 44, Faixa de Camobi km 09, 97105-900, Santa Maria, RS,

Brasil. E-mail: vicentesilveira@smail.ufsm.br. Autor para correspondência. 
elos de processamento nesta cadeia: insumos, agropecuária (produtores), indústria (frigoríficos), distribuição/varejo. Portanto, a cadeia é formada pelo setor à montante da produção (indústrias produtoras de insumos tecnológicos e creditícios), o produtor rural e o setor à jusante da produção (indústrias frigoríficas, curtumes, atacadistas, varejistas e consumidores finais). O produtor permanece entre setores de mercado altamente especializados e não possui capacidade de formular os preços finais de seu produto (MONTOYA \& PARRÉ, 2000). O pecuarista é um tomador de preços, portanto, altamente dependente do poder aquisitivo do mercado consumidor para o qual sua produção se destina (ARBAGE, 2000).

Em dois pontos desta cadeia os preços do produto são públicos: o preço de venda dos animais pelo produtor e o de compra da carne pelos consumidores. No primeiro ponto, os preços podem ser obtidos diretamente junto aos frigoríficos, na internet ou através dos meios de comunicação. Quanto ao preço de compra pelos consumidores, conforme o código de defesa do consumidor, estes estão afixados em lugares de fácil visualização nos diferentes locais de comercialização.

A estrutura de comercialização da carne é basicamente dividida em três tipos de estabelecimentos: supermercados/hipermercados, açougues e boutiques de carnes. Os supermercados/hipermercados correspondem por aproximadamente $60 \%$ das vendas de carne (TELLECHEA, 2001). As exigências dos consumidores têm influenciado o desenvolvimento de alguns tipos de cortes de carne, causando revisões nos conceitos de carcaças, com o objetivo de fornecer uma extensa seleção de peças para açougue, variando em peso, preço e qualidade, para atender aos diferentes pontos de venda, às indústrias ou à exportação (LEDIC et al., 2000).

Como a cadeia é desarticulada e os supermercados são os responsáveis pela distribuição da grande maioria do produto ao consumidor (TELLECHEA, 2001), de uma forma geral, são eles que estabelecem as regras na cadeia da carne bovina e tem um papel muito significativo na definição dos preços praticados em todos os segmentos dessa cadeia. Esta afirmativa está baseada no fato de que o consumidor é o regulador de preços. A elevação do preço do produto ao consumidor final imediatamente reflete na redução ou, até mesmo, na estagnação das vendas. O consumidor é sensível aos aumentos de preços e, como estes mantêm uma relação muito próxima dos supermercados, repassam os efeitos da "ponta” para os demais elos da cadeia produtiva (RIO GRANDE DO SUL, 2003).
Quanto à venda dos animais pelos produtores, vem ocorrendo também uma mudança no modo de comercialização. Anteriormente, a venda ocorria baseada no peso vivo do animal antes do embarque para o frigorífico. Entretanto, cada vez mais, a compra dos animais está condicionada ao rendimento e à qualidade de carcaça obtida no frigorífico. Estimase que este modo de comercialização responda por mais de $60 \%$ nas transações realizadas pelos frigoríficos no Rio Grande do Sul.

Para produzir o animal para abate, o produtor tem um custo de produção que, no momento da venda, precisa ser "repassado” para a indústria. Por sua vez, a indústria é responsável pela transformação em produto carne, que será distribuído ao estabelecimento varejista. Durante este processo, há custos para que o produto vivo (boi/vaca) se transforme em alimento para o consumidor (cortes de carne bovina). O objetivo deste trabalho, portanto, está em verificar em que medida os preços pagos pelos consumidores, ponto final da cadeia, estão associados aos recebidos pelos produtores.

\section{MATERIAL E MÉTODOS}

A pesquisa foi realizada mensalmente, durante o ano de 2005, com a coleta do preço médio da carne bovina em dois pontos da cadeia produtiva: com o produtor e com o consumidor. Na obtenção do preço médio do quilo do boi vivo recebido pelos produtores, formam considerados os preços coletados pela EMATER-RS, os quais foram disponibilizados pelo Centro Integrado de Ensino Pesquisa e Extensão Rural - CIEPER, Convênio UFSM/EMATER. Para a transformação do valor recebido pelo peso vivo do animal em valor recebido por quilo de carcaça, considerou-se um rendimento de $52 \%$, baseado estenos trabalhos de VAZ et al. (2002); PÖTTER \& LOBATO (2003); VAZ \& RESTLE (2005) e MENEZES et al. (2005).

O preço dos diferentes cortes de carne pago pelo consumidor foi coletado por pesquisa mensal de preços, em quatro supermercados de Santa Maria. Inicialmente, o recolhimento de dados nos estabelecimentos comerciais consistiu em um levantamento dos preços dos cortes da carcaça de um bovino, utilizando os mesmos cortes considerados na CPI das Carnes (RIO GRANDE DO SUL, 2003). Entretanto, foi necessária a adaptação dos cortes devido às características do mercado local. Outro fator detectado foi a necessidade da obtenção da participação proporcional dos diferentes cortes na composição final da carcaça, visto que os dados de pesquisa referentes a estas proporções não

Ciência Rural, v.37, n.4, jul-ago, 2007. 
correspondem aos cortes efetivamente comercializados nos supermercados locais. Com a contribuição de dois supermercados, acompanhou-se a decomposição de quatro carcaças nos diferentes cortes.

Depois de obtidos os valores percentuais dos diferentes cortes na composição da carcaça, estes valores foram multiplicados pelo preço pago pelo consumidor, obtendo-se assim os preços e as proporções dos cortes referentes ao valor ajustado de um quilo de carcaça pago pelo consumidor.

Foi utilizado o programa NCSS 6.0 (NCSS, 1995) para a obtenção do coeficiente de correlação de Pearson para medir a associação e a força entre as duas variáveis em estudo: o preço pago pelo consumidor (PPC) e o recebido pelo produtor (PRP).

\section{RESULTADOS E DISCUSSÃO}

Na obtenção do preço da carcaça pago pelo consumidor, tornava-se necessário o conhecimento do percentual dos diferentes cortes na composição final da carcaça. Inicialmente, obtiveram-se os percentuais dos componentes da carcaça: dianteiro, costilhar e traseiro, os quais tinham valores de rendimento próximos aos descritos por VAZ \& RESTLE (2005) e os de MENEZES et al. (2005), e semelhantes ao descritos pela CPI das carnes (RIO GRANDE DO SUL, 2003), respectivamente, 38, 15 e 47\%. Assim, como as partes principais da carcaça estavam de acordo com os dados de literatura, foram realizados os cortes de cada componente da carcaça, ou seja, como os supermercados fracionam a mesma, conforme pode ser observado na tabela 1.

Após obtidos os valores percentuais dos cortes e dos preços pagos pelo consumidor, tornou-se possível verificar a contribuição sobre o valor total, de cada parte da carcaça, ao longo do ano de 2005 (Figura 1). Verifica-se uma baixa variação percentual das partes ao longo do ano na contribuição do preço total. $\mathrm{Na}$ média, o dianteiro contribui com 26,10\%, o costilhar com $13,40 \%$ e o traseiro com $60,50 \%$ do preço total da carcaça. Quando comparado ao levantamento relatado pela CPI das carnes (RIO GRANDE DO SUL, 2003), a contribuição do traseiro foi superior e a do dianteiro inferior; porém, a contribuição de 13,40\% do costilhar foi semelhante à da CPI de 13,34\%. Este fato provavelmente esteja ligado ao perfil da cidade de coleta dos dados, visto que VIANA \& SILVEIRA(2005) demonstraram em trabalho com coletas de dados realizadas em Porto Alegre, Santa Cruz do Sul, Dom Pedrito e Santa Maria, que as cidades de Porto Alegre e Santa Cruz do Sul obtinham os preços mais elevados por quilograma de carne, enquanto que a cidade de Santa Maria obtinha o menor preço entre os municípios pesquisados. Desse modo, é possível inferir que o poder aquisitivo da população interfere nos preços dos diferentes cortes. ARBAGE (2000) também comenta a importância do poder aquisitivo do mercado consumidor na remuneração dos produtos primários.

$\mathrm{O}$ preço recebido pelo produtor (PRP) e o pago pelo consumidor (PPC), ao longo do ano, são apresentados na figura 2. Nota-se claramente o efeito

Tabela 1 - Participação percentual dos diferentes cortes na carcaça bovina comercializados nos supermercados de Santa Maria.

\begin{tabular}{|c|c|c|c|c|c|}
\hline \multicolumn{2}{|c|}{ Dianteiro } & \multicolumn{2}{|c|}{ Costilhar } & \multicolumn{2}{|c|}{ Traseiro } \\
\hline Corte & Percentual & Corte & Percentual & Corte & Percentual \\
\hline Agulha & 11,19 & Costela & 5,99 & Alcatre & 2,48 \\
\hline Peito & 7,34 & Costela desossada & 3,16 & Coxão-de-Dentro & 6,29 \\
\hline Paleta & 10,79 & Vazio & 1,83 & Coxão-de-Fora & 2,94 \\
\hline Músculo & 4,16 & Recorte & 0,40 & Contrafilé & 4,62 \\
\hline Osso & 3,63 & Osso & 0,60 & Filé mignon & 2,18 \\
\hline \multirow[t]{9}{*}{ Sebo } & 1,29 & Sebo & 1,92 & Patinho & 3,65 \\
\hline & & & & Tatu & 1,64 \\
\hline & & & & Maminha & 1,10 \\
\hline & & & & Picanha & 1,39 \\
\hline & & & & Chuleta & 6,01 \\
\hline & & & & Músculo & 2,86 \\
\hline & & & & Recorte & 2,03 \\
\hline & & & & Osso & 7,67 \\
\hline & & & & Sebo & 2,83 \\
\hline Total & 38,40 & Total & 13,90 & Total & 47,70 \\
\hline
\end{tabular}

Ciência Rural, v.37, n.4, jul-ago, 2007. 


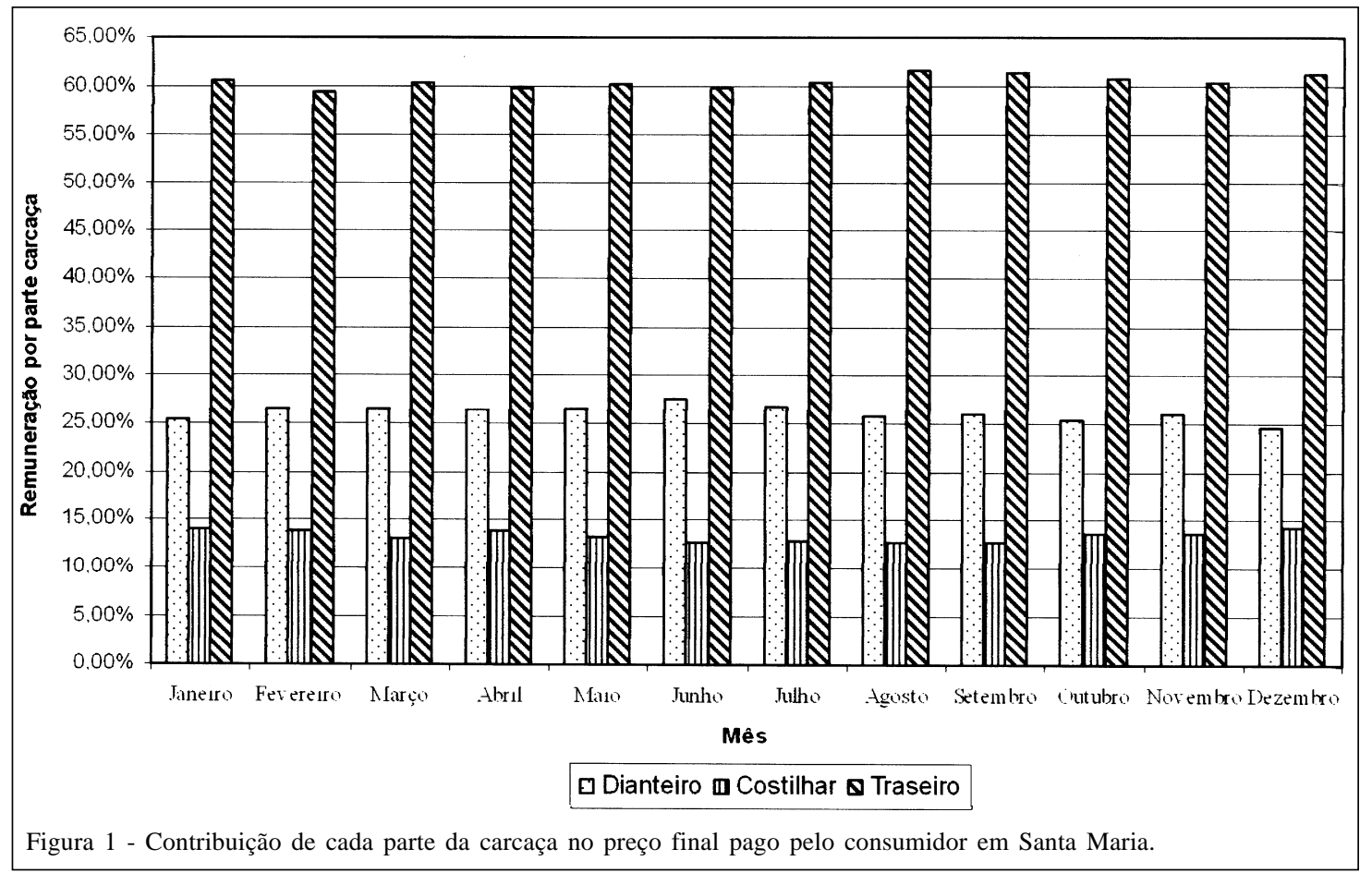

do poder aquisitivo da população como importante fator a influenciar o preço do produto. O preço alcança o seu pico no mês de dezembro, $\mathrm{R}$ 5,56, coincidindo assim com a época em que o consumidor aumenta o seu poder aquisitivo em função do décimo terceiro e, em alguns casos do abono de férias.

Por outro lado, o preço recebido pelo produtor está diretamente ligado ao sistema de

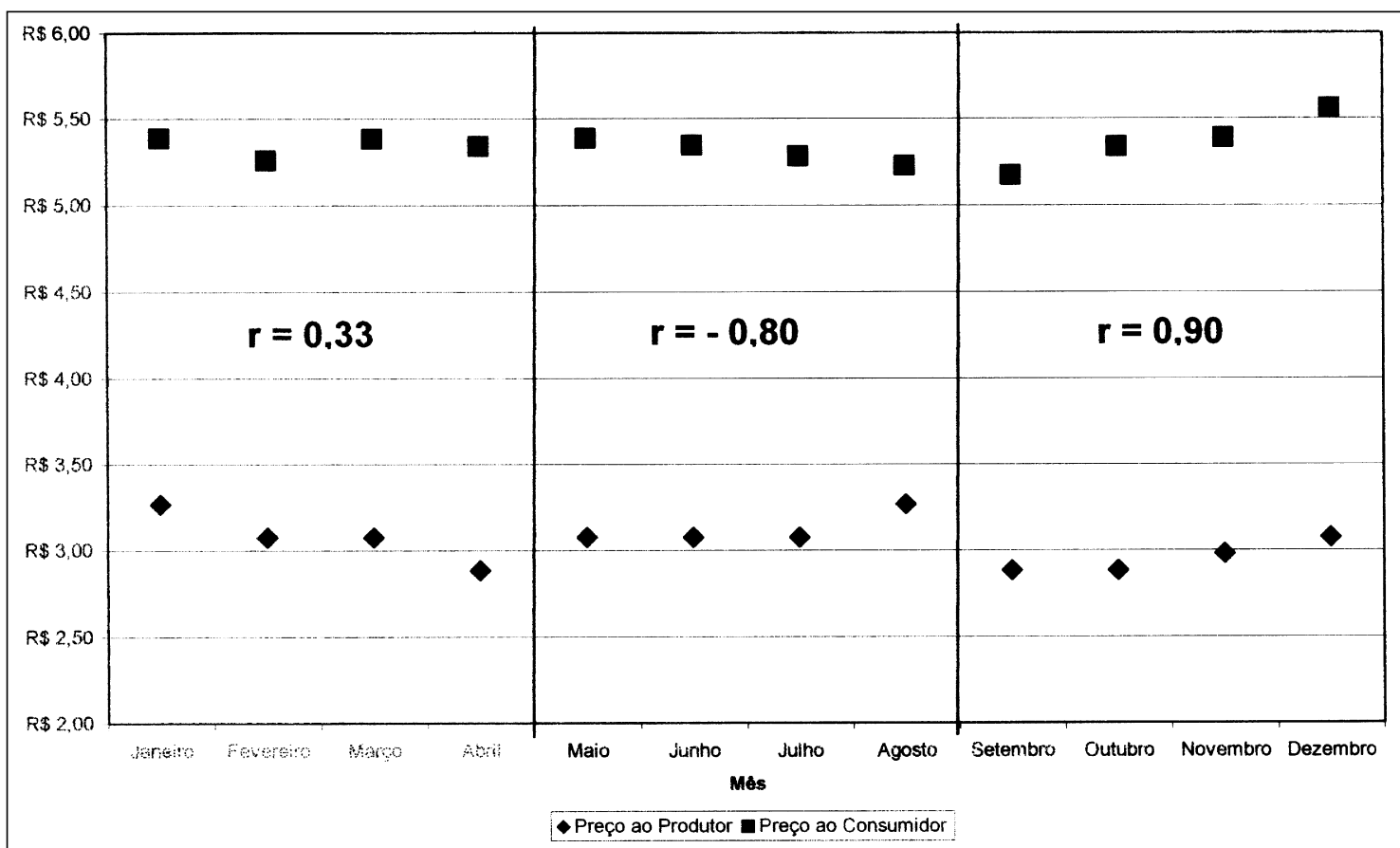

Figura 2 - Preço médio pago por quilo de carcaça ao produtor no Rio Grande do Sul e do preço do quilo pago pelo consumidor em Santa Maria, com respectivos coeficientes de correlação quadrimestrais. 
produção. Assim, verifica-se a menor cotação nos meses de abril, outubro e novembro. No mês de abril, o aumento da oferta ocorre por fatores como necessidade de ajuste de carga nos campos nativos e pela oferta de animais prontos para o abate com alimentação exclusiva em campo nativo. Nos meses de outubro/novembro, é necessária a retirada dos animais para a implantação de lavouras, no caso dos sistemas de produção integradas lavoura - pecuária, aumentando a oferta de animais prontos para o abate. O maior PRP ocorreu em janeiro, R\$1,70 por quilo vivo. No mês de janeiro, além dos fatores produtivos (problemas de crescimento de pastagens cultivadas e nativas), reduzindo assim a oferta, pode-se inferir ainda que a demanda dos consumidores a partir do maior consumo de carne influenciam a elevação do preço a nível de produtor.

Com referência à associação entre PPC e PRP, optou-se, depois de observada a relação mensal, pela divisão do ano por quadrimestres (Figura 2). No primeiro quadrimestre do ano, a relação apresentou-se fraca $(r=0,33)$, o que pode ser atribuído ao fato de que, nesta época do ano, ocorre uma acomodação do mercado após o período das festas de final de ano e férias, conforme o discutido anteriormente. Entretanto, no segundo quadrimestre, a relação pode ser considerada forte e negativa $(\mathrm{r}=-0,80)$, decorrente do fato de que a oferta apresenta-se reduzida por compreender o período de inverno, o que dificulta a aquisição de animais prontos para o abate pelos frigoríficos. Por outro lado, a concorrência com outras carnes e a renda familiar dificultam reajustes de preços ao consumidor. Pode-se observar que, no terceiro quadrimestre do ano, a correlação apresenta-se positivamente e extremamente forte entre PPC e PRP $(\mathrm{r}=0,90)$. O aumento de preço se manifesta tanto ao nível de consumidor como ao nível de produtor.

O preço coletado no varejo foi somente o da carne como produto final da cadeia. Os subprodutos comestíveis e não-comestíveis que correspondem a um acréscimo de $12 \%$ são considerados no cálculo conforme os dados da CPI da Carne (RIO GRANDE DO SUL, 2003). O valor médio calculado referente ao setor a jusante foi de 48,96\%, com um máximo de 51,79\% em abril e um mínimo de 44,18\% em agosto. O valor médio está bem próximo daquele citado por GASQUES et al. (2004) para o setor a jusante da pecuária, de 50,14\%.

A amplitude de 7,61 pontos percentuais significa a margem que o setor a jusante trabalha para ajustar a oferta por parte dos produtores e a demanda dos consumidores, ficando claro que os meses de abril e agosto são, respectivamente, o melhor e o pior mês para o setor na cadeia da carne bovina. A baixa rentabilidade do setor industrial pode ser atribuída à pequena margem de valor agregado da carne bovina porque, tradicionalmente, essa ainda é comercializada em forma de carcaça, dividida em traseiro, dianteiro e costela, apenas poucos frigoríficos comercializam carne em cortes e/ou produtos de maior valor agregado (RIO GRANDE DO SUL, 2003). Ao contrário do que ocorre, por exemplo, na cadeia de carne de aves (FLORES et al., 2006).

\section{CONCLUSÕES}

O setor a jusante na cadeia bovina tem função reguladora do preço final ao consumidor, com uma margem de operação de 7,61 pontos ao longo do ano. Nos três quadrimestres ao longo do ano, a associação entre o preço recebido pelo produtor (PRP) e o pago pelo consumidor (PPC) teve um comportamento diferenciado. As associações verificadas foram fraca, negativamente forte e positivamente muito forte para o primeiro, segundo e terceiro quadrimestres respectivamente.

\section{REFERÊNCIAS}

ARBAGE, A.P. Economia rural: conceitos básicos e aplicações. Chapecó: Universitária Grifos, 2000. 305p.

FLORES, F. et al. Opções de produtos e variações de preços da carne de frango no mercado de Santa Maria-RS. In: JORNADA ACADÊMICA INTEGRADA DA UFSM, 20., 2006, Santa Maria, RS. Anais... Santa Maria: Pró-reitoria de Pós-graduação e Pesquisa, 2006. (CD-ROOM)

GASQUES, J.G. et al. Desempenho e crescimento do agronegócio no Brasil. Brasília: Instituto de Pesquisa Econômica Aplicada (IPEA), 2004. Texto para Discussão, 1009. 43p. Capturado em 18 mar. 2005. Online. Disponível na Internet http://www.ipea.gov.br.

LEDIC, I.L. et. al. Rendimento integral de bovinos após abate. Ciência e Agrotecnologia, v.24, n.1, p.272-277, 2000.

MENEZES, L.F.G. de et al. Características da carcaça de novilhos de diferentes grupos genéticos, terminados em confinamento, recebendo diferentes níveis de concentrado. Ciência Rural, v.35, n.5, p.1141-1147, 2005.

MONTOYA, M.A.; PARRÉ, J.L. O agronegócio brasileiro no final do século $\mathbf{X X}$ : estrutura produtiva, arquitetura organizacional e tendências. Passo Fundo: UPF, 2000. 2v. 337p.

NCSS 6.0. Statistical system for Windows. Kaysville, Utah: Number Cruncher Statistical Systems, 1995. 1558p.

PÖTTER, B.A.A.; LOBATO, J.F.P. Desempenho e características quantitativas de carcaça de novilhos Braford desmamados aos 100 ou 180 dias de idade e abatidos aos 13-14 meses. Revista Brasileira Zootecnia, v.32, n.5, p.12201226, 2003. 
RIO GRANDE DO SUL. Assembléia Legislativa. CPI das carnes relatório final. Porto Alegre, 2003. 764f. Acesso em 15 jun. 2004. Online. Disponível na Internet: http:// www.al.rs.gov.br.

TELLECHEA, F. Análise dos custos de transação no setor industrial da cadeia produtiva de carne bovina no Rio Grande do Sul. 2001. 98f. Dissertação (Mestrado em Economia Rural) - Curso de Pós-graduação em Economia Rural, Universidade Federal do Rio Grande do Sul.

VAZ, F.N. et al. Características de carcaça e da carne de novilhos filhos de vacas $1 / 2$ Nelore $1 / 2$ Charolês e $1 / 2$ Charolês $1 / 2$
Nelore acasaladas com touros Charolês ou Nelore. Revista Brasileira Zootecnia, v.31, n.4, p.1734-1743, 2002.

VAZ, F.N.; RESTLE, J. Características de carcaça e da carne de novilhos Hereford terminados em confinamento com diferentes fontes de volumoso. Revista Brasileira Zootecnia, v.34, n.1, p.230-238, 2005

VIANA, J.G.A., SILVEIRA, V.C.P. A influência das diferentes regiões econômicas do Rio Grande do Sul no preço pago pela carne bovina em nível de varejo. In: SEMINÁRIO DE INICIAÇÃO CIENTÍFICA DA UNISC, 11., 2005, Santa Cruz do Sul, RS. Anais... Santa Cruz do Sul: Pró-reitoria de Pesquisa e Pós-graduação, 2005. (CD-ROOM). 